\title{
A BRIEF HISTORY OF RATIONALITY: REASON, REASONABLENESS, RATIONALITY, AND REASONS
}

\author{
KARL SCHAFER \\ University of California, Irvine \\ Department of Philosophy \\ 85 Humanities Instructional Building \\ Irvine, CA 92697-4555 \\ U.S.A. \\ schaferk@uci.edu
}

\author{
Article info \\ CDD: 149.7 \\ Keywords: \\ Rationality \\ Reason \\ Reasons \\ History of Modern Philosophy \\ Rationalization
}

Received: 31.07.2018; Accepted: 13.08.2018

DOI: http://dx.doi.org/10.1590/0100-6045.2018.V41N4.KS

Abstract: The title really says it all, doesn't it?

I'd like to tell you a story. It is, in a sense, a small part of the history of philosophy. But if it's history I'll be narrating, it's history at a level of generality and abstraction that makes its virtues as a piece of historical scholarship dubious at best. So perhaps it's better to view what follows as a sort of philosophical bedtime story. One with a moral or two, to be sure, and hopefully with some insights about the actual development of certain philosophical concepts, but also with 
a noticeable amount of distortion and simplification along the way.

The tale I have in mind concerns a cluster of concepts namely, the concepts of reason, reasoning, reasons, reasonableness, rationality, and the like. That these concepts have some sort of systematic connection with one another is hardly news. Indeed, a great deal of electronic ink has been spilt in recent years arguing about just how we should understand their relationship. Should we, for example, adopt a "reasons-first" perspective, on which the fundamental concept in this area is the concept of a reason in the sense of a consideration that counts in favor of some attitude or action? ${ }^{1}$ If so, then we will quickly find ourselves in the business of giving an account of the other concepts on this list - rationality, reasoning, and so on - in terms of reasons in this "consideration sense". 2

But perhaps this gets things the wrong way 'round, and it is really rationality that has priority over reasons in this network? If so, we will be interested in a different sort of explanatory task, one which attempts to provide an account of reasons in terms of claims about rationality. ${ }^{3}$ Or perhaps

\footnotetext{
${ }^{1}$ Of course, these questions can be raised at the level of terms or concepts and at the level of properties. For ease of expression, I'll focus mostly on relationships between concepts here. But it is important to stress that we might raise the same sorts of questions about properties as well, and that the order of priority between properties might be different from that between concepts.

${ }^{2}$ For the focus on reasons, see, among many other examples, Parfit(2011) and Scanlon(2013). For two recent attempts to define rationality in terms of responsiveness to reasons, see Kiesewetter(2017), Lord(2018).

3 For a classic, broadly "Humean" view of this sort, see Smith(1995). For an overview of more Kantian work in this general vein, see Schafer(2015a,b).
} 
it is really the concept of reasoning that is most basic here?4 Or the concept of reason as a faculty? ${ }^{5}$ Or something else entirely?

All of these positions have their defenders in the contemporary debate. But my goal here is not to engage directly with their arguments. Instead, I want to take a step back from this conversation to consider how our understanding of these relationships has evolved over time. In this way, my aim is to provide some context for these debates by charting a bit of the history of the interaction between these concepts.

As already noted, in doing so, I will operate at a very high - and thus, inevitably, distorting - level of abstraction. But I hope the general trends I describe will be recognizable to students of the history of modern philosophy in the West. Of course, this leaves it open whether this sense of recognition is entirely to be trusted. For it might be that the story I am telling here feels familiar - less because it is part of the historical truth - and more because it is part of contemporary philosophy's preferred mythology about its own origins. A bit of meconnaissance, as our friends in France might say.

To be honest, I'm not sure what exactly the mix of history and myth in my story is. But whatever the ratio of these elements, I think this story does have significance for our understanding of these debates. For, one thing I do think is

\footnotetext{
${ }^{4}$ For recent views that attempt to define reasons in terms of reasoning see, for example, Setiya(2014) and Silverstein(2016). Compare McHugh and Way(forthcoming).

${ }^{5}$ For a view that treats the faculty of reason as fundamental, see Schafer(forthcoming-a,b,c). For a view that attempts to define rationality in terms of reason as a capacity, but then attempts to understand that capacity in terms of reasons in the consideration sense, see Kauppinen(2018). For a related account of rationality as a virtue, see Wedgwood (2018).
} 
true, and which is too often forgotten within the contemporary debate, is that the dominant understanding of these concepts and their relationships has been far from static over the history of philosophy. Thus, by considering the following "conjectural history of philosophy", I believe we can gain some genuine insights into what should, and should not, be taken for granted about these issues.

My narrative here will involve four stages, which (in the spirit of summer blockbusters) we might label as follows: (i) The Age of Reason, (ii) The Rise of Reasonableness, (iii) The Triumph of Rationality, and (iv) The Return of Reasons. To preserve some distance from this tale, I'm going to present these episodes as though they occurred within a fictional world - call it "Atwater". As just noted, many aspects of Atwater's history should seem familiar. But at the same time, it is far more linear and straightforward than the history of our actual world. In this way, Atwater's history might be taken to represent a simplified model of certain aspects of the history of our world. I think this model contains important insights, but in presenting it as a kind of useful fiction, I want to stress that it shouldn't be taken to be more than a helpful model.

\section{THE AGE OF REASON}

The first episode in our story begins at the threshold of Atwater's modern age. At this time, both psychology and philosophy in Atwater gave a central role to the notion of a mental faculty or capacity. ${ }^{6}$ In general, such faculties were

\footnotetext{
${ }^{6}$ The centrality of the faculty sense of reason during this period can be seen both in philosophy and in the more general etymological data. For example, the Online Etymological Dictionary describes the first recorded uses of "reasonable" (c. 1300) as meaning "having sound judgment, sane, rational". And it describes the first uses of "rational" (late 14c) as meaning "pertaining to
} 
conceived of in broadly active and teleological terms. That is, each faculty was conceived of as having a distinctive aim or function - such that, when that faculty was functioning properly, its activities would contribute to this telos.

First among these mental faculties and capacities was the faculty of reason. Everyone, not surprisingly, agreed that one of the primary activities of this faculty was the activity of reasoning - of drawing conclusions from premises - and they agreed that the function or telos of this faculty had something to do with knowledge or understanding. But beyond these basic points of agreement, just what the faculty of reason involved, and how far its reach extended, was the topic of much debate. Some, call them "rationalists", thought of reason or the intellect as enabling us to gain certain knowledge of deep, substantive truths via some form of intellectual intuition. Others, call them "empiricists", had a much more modest conception of this faculty, on which it was limited to perceiving (or establishing) relationships between ideas acquired via the senses. But almost all philosophers operated within a broadly faculty- or capacitytheoretic paradigm in making these sorts of claims. And almost all of them, no matter how empiricist they might be, thought of the faculty of reason as an especially important topic of philosophical and normative conversation.

Most importantly for our purposes, the philosophers of this era did not merely give a central role to the faculty of reason in their psychological theorizing, they also placed this concept at the center of their thinking about more apparently normative matters, like the nature of rationality or what we have reason to do or believe. For example, when one of the

reason" and (mid-15c) "endowed with reason". Thus, from very early on, the meaning of concepts like rational or reasonable was closely tied to the notion of reason as a faculty (or collection of faculties). 
great anti-rationalist philosophers of this age attacked the pretentions of rationalist moralists, he wrote the following:

Actions may be laudable or blameable; but they cannot be reasonable or unreasonable: Laudable or blameable, therefore, are not the same with reasonable or unreasonable. ${ }^{7}$

While many scholars in Atwater continue to read this passage as an endorsement of the claim that there are no normative reasons for action, once read in its context, it is clear that it is not directly concerned with practical reasons in the contemporary sense of "considerations that count in favor or against some action". ${ }^{8}$ Rather, this philosopher's primary concern in such passages is with the nature of reason as a faculty. That is, in claiming that actions are never "reasonable or unreasonable", he was claiming, in effect, that the faculty of reason never (on its own) speaks for or against some action. ${ }^{9}$ In this sense of "reasonable", to call something "reasonable" is just to say that it is in accordance with a properly functioning faculty of reason (however this is understood).

Thus, while such passages certainly express a robust antirationalism, it is primarily concerned with the possibility of practical reason as a faculty, as opposed to the possibility of practical reasons in the "consideration sense" predominant today. ${ }^{10}$ Notably, this focus on the faculty of reason was

\footnotetext{
${ }^{7}$ Hume(2000), 3.1.1.10.

8 In this regard, we are fortunate that the state of historical scholarship in our world has advanced somewhat beyond its state in Atwater.

${ }^{9}$ See, e.g. Sayre-McCord(2008) and Schafer(2015c).

10 Which is not, of course, to say that there is no connection between these questions.
} 
common to both those skeptical of reason's philosophical or normative significance and those who set out to defend its importance. For example, perhaps the greatest opponent of our anti-rationalist characterized the foundations of his own philosophical project as follows:

But all human insight is at an end as soon as we have arrived at basic powers or basic faculties; for there is nothing through which their possibility can be conceived, and yet it may not be invented and assumed at one's discretion. ${ }^{11}$

As this quote indicates, for this defender of reason, philosophy itself "bottomed out" in the nature of certain basic faculties - and first among them was the faculty of reason itself. On his conception of philosophy, then, such basic faculties might be used to explain the possibility of other things - for example, the world of appearances or the

${ }^{11}$ Kant(1999), 5:46-7. Compare:

In this way the a priori principles of two faculties of the mind, the faculty of cognition and that of desire, would be found and determined as to the conditions, extend, and boundaries of their use, and a firm basis would thereby be laid for a scientific system of philosophy, both theoretical and practical. (5:12)

And:

There is thus revealed a system of the powers of mind, in their relation to nature and freedom, both of which have their own special, determining principles a priori and therefore constitute the two parts of philosophy (the theoretical and the practical) as a doctrinal system, and at the same time a transition by means of the power of judgment ... (20:247) 
categorical imperative - but their possibility could not itself be explained (at least by us) in more fundamental terms. ${ }^{12}$ Thus, this lover of reason also endorsed - not just the claim that reason as a faculty plays a central role in philosophical and normative theorizing - but also the stronger claim that this role is in some sense a foundational one.

\section{THE RISE OF REASONABLENESS}

This, then, is where our story begins - with a time during which the notion of reason as a faculty was at the center of the network of concepts we are exploring. Our story concerns how Atwater moved from this state to one (much like the present state of affairs in the actual world) in which this notion plays a much more marginal role.

Not surprisingly, one very significant part of this story involved a series of changes within Atwaterian psychology. For, much as in our world, over the period we are exploring, the status of faculty psychology within Atwater was increasingly called into question from several directions. And as this occurred, it was only natural that the place of facultytheoretic notions should also have been called into question in other areas of thought, like more normative areas of philosophy, as well. ${ }^{13}$

12 Kant's definition of imperatives or ought claims in terms of the faculty of reason is, of course, particularly important for our story here.

${ }^{13}$ For example, one of the founding figures of modern psychology in Atwater, described their relationship to "faculty psychology" as follows:

It is probable that the mental faculties stood originally not merely for different parts of the field of internal experience, but for as many different beings; though the relation of these to the total 
But this version of our story - in terms of the gradual replacement of faculty psychology with something "more modern" - misses much of what is philosophically interesting in these transformations. ${ }^{14}$ So, to get a better grip on the dynamics at work here, I want to focus on how the predominant understanding of rationality began to shift during the period of Atwater's history that corresponds to our own "high Enlightenment". In histories of Atwater, this era is often referred to as "the age of reason". But while it was an era with a great affection for reason, it was also a period in which traditional conceptions of reason and rationality came under increasing strain.

This, in considerable part, was the product of the emergence of a new conception of "reasonableness", which developed in tandem with early forms of probability theory. ${ }^{15}$ The key feature of this new notion of reasonableness was that, contrary to previous models of rationality, it allowed reasonable belief to be based on merely probable, as opposed to demonstratively certain, grounds. Thus, the traditional conception of rationality, which focused on modes of intuition and reasoning capable of

being, the mind or spirit, was not conceived of in any very definite way. But the hypostatisation of these concepts lies so far back in the remote past, and the mythological interpretation of nature is so alien to our modes of thought, that there is no need here to warn the reader against a too great credulity in the matter of metaphysical substances. (Wundt 1893. 18-19)

${ }^{14}$ In addition, as we will discuss below, with the rise of the idea of the mind as modular, talk of mental capacities or faculties (in some sense) no longer seems so outdated.

15 See Daston(1988), which this section draws heavily upon. For further background see Hacking(1975). 
producing certain knowledge, was gradually replaced by a conception of reasonableness, on which being reasonable was fundamentally a matter of responding correctly to uncertainty in the face of less than fully conclusive evidence.

The rise of this conception of reasonableness was associated with important developments in areas ranging from theology to political economy. ${ }^{16}$ But a few aspects of it are particularly important for our story here. First, the rise of this probabilistic conception of reasonableness was closely tied to a growing skepticism about the forms of intellectual intuition or rational insight that were characteristic of more robust, rationalist conceptions of reason as a faculty. Indeed, the focus on probability was in some sense a replacement for more robust conceptions of reason or the intellect. For, in the absence of the forms of rational intuition that produced certain knowledge of substantive truths, the best human beings could do seemed to be to respond as reasonably as possible to our mixed and uncertain empirical evidence about the nature of things. Thus, as the scope of reason to deliver certainty become more limited, it was only natural for an increasing interest in merely probable grounds for belief to take its place.

In this way, the move to a probabilistic conception of reasonableness was part of a general trend towards a more modest understanding of the faculty of reason and, by extension, rationality itself. But at the same time, the emergence of this new conception of reasonableness put pressure on the traditional link between evaluative notions like reasonableness and the concept of reason as a faculty. For insofar as the faculty of reason remained limited to demonstrative (as opposed to probable) reasoning, any expansion of reasonableness to include probabilistic grounds

16 For the history of "reasonable" in a legal context, see Waldman(1959). 
for belief called into question the tradition connection between the faculty of reason, on the one hand, and the evaluative or normative notion of rationality or reasonableness on the other.

In this way, during this period there was the beginnings of a break between the concept of reason as a faculty and concepts of reasonableness and rationality. But only the beginnings. For this shift in the meaning of "reasonableness" was generally accompanied by a corresponding shift in how the faculty of reason was understood - so that probable, as well as demonstrative, reasoning was included among reason's characteristic manifestations. Here the very antirationalist philosopher we mentioned above again played a central role - developing (as he did) a conception of reason on which the primary manifestation of reason lay in probable reasoning, with demonstrative reasoning relegated to a supporting role. ${ }^{17}$

One final aspect of this new conception of "reasonableness" is worth mentioning before we move on namely, the manner in which it set the stage for future attempts to develop a mathematically precise, formal conception of rationality's demands. This is true, even though the Enlightenment conception of reasonableness was not itself purely formal or mathematical. For instance, the philosophers of Atwater's Enlightenment continued to give an essential role to a faculty for "judgment", which could not be reduced to the application of formally specifiable rules or formulas. ${ }^{18}$ But nonetheless, by linking reasonableness with the mathematical study of probabilities, they paved the way for the development of mathematical models of rationality,

17 See again Hume(2000). Locke's influence here is also, of course, important. But there many other important figures to this story who are less famous today.

18 See Daston(1988) again. For some related discussion, see Herman(1993). 
which would attempt to reduce rationality to a set of formulas or formally specifiable rules.

In all these ways, this new conception of reasonableness contained the seeds of the rise of formal conceptions of rationality, which will be the focus of the next chapter of our story. As noted, this strained the historical connection between reasonableness/rationality and reason as a faculty. But nonetheless this connection remained largely in place during this period. To see these notions really come apart, we need to move to the next stage of our narrative - in which the conception of reasonableness we have just been discussing develops into a purely formal conception of rationality, decoupled both from the faculty of reason and any substantive claims about what it is rational to believe or do.

\section{THE TRIUMPH OF RATIONALITY}

This next chapter of Atwater's story was characterized by the sort of process that one of Atwater's greatest social theorists called "rationalization". ${ }^{19}$ Or, more precisely, it was characterized by one particular form that this process might take. I say this because, for this theorist, there was a sense in which any system of ultimate ends or values corresponded to a possible form of "rationalization"; different areas of human life are capable of being "rationalized in terms of very different ultimate values and ends." 20

In keeping with this thought, our theorist conceived of rationality itself as coming in a variety of different forms. On the one hand, there was "instrumental rationality", which involved the organization of life around the relation of means to ends. But there was also the related, but distinct phenomenon of "formal rationality" - that is, the organization of life around ever more general and abstract

${ }^{19}$ Compare Weber(2002).

${ }^{20}$ Weber(2002), 27. 
principles or rules. ${ }^{21}$ And, behind both of these, there was "substantive rationality" - i.e. the orientation of life towards non-instrumental, and often less than fully formalizable, values. What unified these different forms of "rationalization", for our theorist, was that they all, in their own way, attempted to make the world more intelligible, predictable, and controllable. ${ }^{22}$

Given all this, it is no surprise that, for our theorist, the history of "rationalization" in all its forms was coextensive with the history of human culture. And yet, despite the universality of "rationalization" in this broad sense, our theorist also took at least certain aspects of rationalization to have reached their fullest expression in Atwaterian modernity. In other words, as a philosopher deeply influenced by our theorist put it, it was characteristic of modernity that "the institutionalization of purposive-rational economic and administrative action" reached an everintensifying high point. 23

This distinctively modern form of rationalization involved a self-reinforcing process by which ever greater areas of life were organized in accordance with two related, but distinct,

${ }^{21}$ In focusing on these forms of "rationality", Weber is of course showing his neo-Kantian side. Note that the very notion of "formal rationality" raises deep philosophical questions about what it is for something to follow from a rule or principle. So, it is no surprise that Weber, independently of Wittgenstein, wrestled with the nature of rule-following in his work. As we'll see the vagueness of this notion of "formal rationality" will be important for our story, for it sets up the task of developing a precise conception of "formal rationality" as one of the problems to be solved via "rationalization" and, indeed, "meta-rationalization".

${ }^{22}$ This is not meant to be an exhaustive characterization of Weber's conception of rationality, which continues to be the subject of much debate. For some scholarly discussion, see Levine(2005).

${ }^{23}$ Habermas(1985) 
forms of rationality: (i) instrumental (means-ends) rationality and (ii) "formal" (rule-governed) rationality. ${ }^{24}$ This "rationalization of society" might come in the form of an expansion of the areas of society subject to economic calculation. Or it might be a matter of the creation of new system of rules of the sort characteristic of administrative bureaucracy. But, in both cases, according to our theorist, the process served similar ends - namely, the transformation of society into a "more rational" form - that is, a form governed by principles or formulas that allow for the prediction and control of human action. ${ }^{25}$ This, then, became (at least in theory) a world in which,

... there are no mysterious incalculable forces that come into play, but rather that one can, in principle, master all things by calculation. This means that the world is disenchanted. One no longer need have recourse to magical means in order to master or implore the spirits, as did the savage, for whom such mysterious powers existed. Technical means and calculations perform the service. ${ }^{26}$

In this way, this process of "rationalization", for our theorist, was closely associated with a gradual, but persistent undermining of traditional forms of intrinsic value or meaning. In particular, insofar as this modern form of

24 The relationship between these two forms of "modern rationality", both in Weber and in general, is the subject of much debate. But for our purposes here, the details of these debates won't matter too much.

${ }^{25}$ For a detailed discussion of this process of "rationalization" in $20^{\text {th }}$ century America, see Daston et al(2013). Although note that, to my mind, they tend to overestimate the role of Cold War history in these transformations.

26 Weber(1994). 
"rationalization" was focused on instrumental and formal rationality, it tended to call into question forms of value that resisted explanation in terms of either means-ends relations or abstract rules. In this sense, the process of "rationalization" was also one of "disenchantment" - a process in which traditional forms of life lost the ability to give meaning and value to life.

Now, it is no surprise that this process of increasing rationalization had a deep impact on how Atwaterians conceived of rationality itself. Indeed, this process of rationalization impacted their understanding of rationality in at least two ways. First, it generated pressure in favor of conceptions of rationality that emphasized the two "modern" modes of "rationalization" just noted over other more traditional forms thereof. But, in addition, the notions of reason, rationality, and the like themselves provided an almost inevitable target for this process of rationalization. ${ }^{27}$ In this way, a central element of this self-reinforcing drive to rationalization was an attempt to rationalize the very notions of rationality which, from the start, informed the process of rationalization itself.

This process of "meta-rationalization" is particularly significant here because there were at least two elements of the traditional conception of rationality that were highly vulnerable to "rationalization" in this sense: (i) its focus on the faculty of reason and (ii) its general sympathy towards more "substantive" conceptions of reason and rationality.

On the first of these points, it is important that the traditional Atwaterian conception of our faculties was one on which these faculties were individuated by their function

27 Indeed, as noted above, the vagueness of early notions of "formal rationality" indicated that there was much work to be done in developing a conception of "formal rationality" that was "formally rational" by its own lights. 
or aim or telos. Unfortunately for such notions, the mode of broadly teleological explanation that was associated with them was one of the primary targets of the process of "rationalization" we are considering. ${ }^{28}$ Thus, as this process progressed, it was only natural for it to generate an increasing skepticism about traditional faculty-theoretic concepts like the concept of reason as a faculty, especially insofar as these concepts appeared to be tied up with an "irrational" commitment to teleological modes of explanation.

At the same time, it is no surprise that this process also led to a growing skepticism about more "substantive" conceptions of "reasonableness" or "rationality" - whether or not these were associated with the faculty of reason. For these notions of reasonableness themselves rested on forms of substantive value that were ripe for "disenchantment". But behind both these tendencies was another dimension of this process that was in some ways more basic. For rationality itself will only be rationalizable in this "modern" sense of the word insofar as we can develop a conception of rationality on which rationality can be given a purely "formal" characterization. That is, to "rationalize rationality" we need to develop a conception of rationality on which it can be characterized in terms of a set of general rules or principles, which fully determine what rationality demands of us. ${ }^{29}$

${ }^{28}$ See, again, the Wundt quotation above.

29 As noted before, this involved developing both a more precise understanding of rationality as formal and a clearer conception of what it meant to call something formal in the first place. So, both rationality and formality were (in a sense) rationalized via this process. Or, that at least was its aim. After all, quite early in its development, serious crises arose for this project, mostly notably Gödel's incompleteness results. But while these results were certainly significant, they did remarkably little to slow the broader 
As we've discussed, this project of (as one early probability theorist put it) reducing "good sense ... to a calculus" was already emerging during the second chapter of our story. ${ }^{30}$ But those early attempts at the "rationalization" of rationality were limited by the mathematics of the time. And in any case, as noted above, the theorists of the Enlightenment did not aim to completely sever the connection between reasonableness and reason as a faculty. Thus, the Enlightenment version of this project remained opposed to the wholescale replacement of the traditional connection between reason and reasonableness with a freestanding conception of rationality, defined solely in terms of certain general rules or principles.

It is only with the rise of modern formal logic, probability theory, decision theory, and early computer science in Atwater, that a good deal of theorizing about rationality become fully committed to this "meta-rationalizing" project. It is only then, in other words, that we find the full development of the idea that:

whatever rationality was, it could be captured by a finite, well-defined set of rules to be applied unambiguously in specified settings-without recourse to the faculty of judgment so fundamental to traditional ideals of reason and reasonableness. ${ }^{31}$

movement towards "rationalization" we have been considering here.

${ }^{30}$ Compare Laplace(2012).

${ }^{31}$ Daston et al(2013), 29. Note that, following Rawls, it is common to claim that this shift was associated with a growing terminological preference for "rationality" as opposed to "reasonableness". But this isn't backed up by the linguistic corpus data, at least in English. 
The power and elegance of this way of conceiving of rationality was as obvious to Atwaterian philosophers as it was to philosophers in our world. But its limitations also quickly attracted criticism. For instance, it was not at all clear whether the resulting minimal conception of rationality could do the normative or evaluative work that was traditionally associated with notions of rationality or reasonableness. Indeed, it seemed to many that a purely formal or mathematical conception of rationality would, of necessity, neuter the critical power of this concept - thereby undermining the very ambitions responsible for much of the process of rationalization itself. In the next, and final, chapter of our story, I want to consider one form this reaction against formal conceptions of rationality took.

\section{THE RETURN OF REASONS}

In the third chapter of our story, then, the traditional connection between reason as a faculty and rationality was largely severed so as to create a conception of rationality that was compatible with the drive towards "rationalization" characteristic of Atwaterian modernity. As just noted, this development left many philosophers in Atwater worried about how to preserve a robust form of rational evaluation and criticism. To accomplish this, a number of philosophers urged their fellows not to confuse the standards of rationality, in this minimal sense, with what is required in order to act or believe in accordance with our epistemic and practical reasons. In particular, they argued that even if rationality is conceived of in quite minimal terms, that does not mean that the constraints placed on us by our reasons for belief and action should be equally minimal. Thus, these "reasons theorists" hoped to save a robust form of rational criticism - namely, criticism on the grounds that one is being unresponsive to one's reasons - by loosening the connection between this 
form of criticism and the sort of criticism that was associated with irrationality in a minimal or formal sense. ${ }^{32}$

This sort of view was developed in variety of different ways. But once fully developed, it tended to take the form of what was often called (most often by its critics) "reasons fundamentalism".33 For the "reasons fundamentalist", reasons were the fundamental normative concept (or relation), and all other normative concepts (or properties) were best defined in terms of them. So, for example, the reasons fundamentalist might define reasonableness in terms of being (disposed to be) properly responsive to one's (possessed) reasons. ${ }^{34}$ Indeed, for the genuine "reasons fundamentalist", facts about reasons were, not just prior to other normative facts, but also impossible to explain in any other terms. On such views, then, explanations within the normative domain bottomed out in certain claims about reasons, and any attempt to explain these facts in nonnormative terms was fundamentally misguided.

Once it is put this way, one thing that is striking about "reasons fundamentalism" is just how radical a rejection of the project of "rationalizing rationality" it involved. For example, while various formal principles of rationality may be part of the fundamentalist's view, these principles will themselves be explained in terms of more fundamental facts about reasons which (for the reasons fundamentalist) resist explanation in any (formal or non-formal) terms. In this way, the reasons fundamentalists saved a robust conception of reasons and rational criticism, but only via the rejection - not just of this or that particular formal conception of rationality

\footnotetext{
32 Perhaps the start of this trend was Rawls's distinction between "rationality" and "reasonableness" in (e.g.) Rawls(1971).

33 Compare Dreier(2014).

${ }^{34}$ Compare, again, Kiesewetter(2017) and Lord(2018).
} 
- but of the very project of "rationalization" that seemed to many to be characteristic of Atwaterian modernity.

Interestingly, this is something that reasons fundamentalists tended to be quite upfront about. For one of the central messages of reasons fundamentalism was that normative explanations must come to an end somewhere, and that this endpoint need not admit of further explanation in non-normative terms. In other words, reasons fundamentalists insisted upon the inevitable limits of rationalization. In this sense, it is no surprise that many reasons fundamentalists were also attracted to some form of quietism about foundational normative or metanormative questions. ${ }^{35}$

In this sense, "reasons fundamentalism" was deeply at odds with the drive towards rationalization that was the focus of our third chapter. But there is another sense in which reasons fundamentalism might be seen as a natural extension of this process of rationalization. For, like the developments in the third chapter of our story, the rise of "reasons fundamentalism" can be seen as a further stage in the breakdown of the traditional network of concepts we have been discussing.

After all, as we've discussed, for most their history, the concepts of reason as a faculty, reasons as considerations, and rationality or reasonableness were closely tied to one another - and got much of their meaning through these connections. But with the rise of purely formal conceptions of rationality, the connections between rationality and the notion of reason as a faculty began to weaken. And with the rise of reasons fundamentalism, so too did the connections between reasons (in the consideration sense) and rationality (in at least one central sense of this term). So, the overall trend, in both our third and fourth chapters, was towards the

35 For some discussion of the sense in which such views are "quietist", see Kremm and Schafer(2016). 
breakdown of the integrity of the network of concepts that traditionally provided these notions with a good deal of their significance. If there is one overall trend of our narrative, I think it is this.

\section{SOME MORALS OF OUR STORY}

This, then, concludes my story. But, as discussed above, the point of spinning this tale was to extract a few morals from it that might be relevant to the contemporary debate about reasons and rationality. To consider what these morals might be, I'll simply assume that the broad outlines of this story map reasonably well onto the actual history of these concepts - and ask what would follow if this were the case.

The first thing that would follow, I think, is a certain skepticism about the contemporary tendency to treat some form of "reasons-first-ism" as the default or obvious position in these debates. For, if anything like the present narrative is right, views that give priority to reasons (in the consideration sense) actually represent a significant departure from the way these concepts have been thought of for most of their history. In short, a focus on the centrality of reasons seems to have been a relatively recent development in these debates, and that should at least give us pause about taking such a view for granted in our theorizing about these questions.

But there is a more general, and much more radical worry about the contemporary debate that this narrative, if true, would suggest. For if this narrative is right, then for most of their history these concepts got their content through their connections with one another, and with the concept of reason as a faculty in particular. And yet, the overall tendency of our story has been towards a weakening, both of these connections in general, and of the role of the concept of reason as a faculty in particular. So, given this, shouldn't we 
be concerned about whether the concepts in this everyloosening network still possess the meaning we, as philosophers, tend to assume they do?

In its most radical form, someone convinced by this worry might find themselves echoing Anscombe's famous claims about "modern moral philosophy". In doing so, they would (in effect) challenge whether it makes any sense to talk of "rationality" or "reasons" once these have been decoupled from the network of concepts we have been considering - and some notion of reason as a faculty in particular. Prompted by such thoughts, such a radical reader of our story might find themselves saying:

The concepts of rationality and reasons ought to jettisoned if this is psychologically possible; because they are survivals, or derivatives from survivals, from an earlier conception of psychology and philosophy which no longer generally survives, and are only harmful without it. ${ }^{36}$

As should be clear, I don't think the present narrative (even if true) would establish anything nearly this strong. But I do think it raises questions about the meaningfulness and usefulness of concepts like rationality in contexts in which they have lost many of their traditional conceptual connections.

Some evidence that these concepts have lost a good deal of their traditional significance can be found in the tendency of contemporary analytic philosophers to treat terms like "rational" as extremely "thin" normative concepts. For example, in his original presentation of his norm-expressivist account of normative discourse, Gibbard treated "rational" as the thin normative term par excellence. In doing so, he provided an account on which, "to call something rational is

${ }^{36}$ Compare Anscombe(1959). 
to express one's acceptance of norms that permit it". ${ }^{37}$ Now, I don't think Gibbard is wrong to think that we sometimes use "rational" in this sort of thin and open-ended way. But it is clear that this use of "rational" is miles away from the traditional conception of rationality, the decay of which we have been exploring here. So, whether for better or worse, Gibbard's understanding of "rational" is indicative of a process by which this term has lost much of its traditional significance.

One might, of course, respond to these concerns by calling into question how important the concept of reason as a faculty ever was to this network of concepts. For instance, one might argue that the important connections here are really between the other concepts in this network, and that the faculty of reason only came to play a central role in this network because of the general importance of facultytheoretic notions during an earlier period of intellectual history. I think there are some prima facie reasons for caution about this line of thought, but it is exactly the sort of question this story should prompt us to think about.

Similarly, given such questions, our narrative also seems to give us some reason to take more seriously views of rationality on which something like the traditional notion of reason as a faculty or capacity does continue to play a central role. For such views would seem to gain at least some prima facie plausibility from the fact that they dominated so much of the history of these concepts. ${ }^{38}$ Moreover, such a "return to reason" no longer seems as psychologically implausible as it once did. For the psychological respectability, both of capacity-theoretic notions and of the notion of reason as a

37 Gibbard(1990), 7. Compare Dogramaci(2015) and Schafer(2014).

38 See Schafer(forthcoming-a,b,c). Compare Kauppinen(2018) and Wedgwood(2018). 
capacity has recently been on the rise. ${ }^{39}$ So it could be that the best way to save a philosophically useful concept of rationality is in fact to return to a conception that gives pride of place to the faculty of reason. ${ }^{40}$

That being said, I want to stress again that I don't think our narrative (even if approximately correct) provides us with clear answers to any of these questions. What is interesting about this story, to my mind, is its ability to raise these sorts of questions - and not its ability to provide answers to them.

For instance, there is a reading of this narrative, on which this process of "rationalization" really goes wrong when it severs "rationality" from the idea of reason as a faculty for reasoning. If something like this is right, then the recent history of metaethics looks like a series of at best partial attempts to appreciate this point. For example, the recent "turn to reasons" is often thought of as a corrective to an "overly formalized" conception of rationality. But if a proper conception of rationality requires an appreciation of the connection between rationality and the faculty of reason, this

${ }^{39}$ Compare Mercier \& Sperber(2017) and Schellenberg(2018)

40 On the other hand, the rehabilitation of talk of capacities or faculties and their functions in psychology has been dominated by two more or less reductive concepts of functions: (i) etiological accounts of functions on which these are understood in terms of natural selection and (ii) systems accounts of functions on which these are understood as ways of describing the role that something plays in some complex system. And, insofar as each of these conceptions of function is purely naturalistic in character, some might question where they provide us with the notion of function that is well suited to play a central role in a network of normative or evaluative concepts like the one we are considering. So, whether the recent willingness to make use of capacity- or facultytheoretical notions in psychology is really so friendly to a return to a more traditional conception of rationality is a complicated question. 
"corrective" misses perhaps the central failing of merely formal conceptions of rationality entirely.

Similarly, while contemporary Kantianism's focus on the constitution of agency may in some ways be an advance over this sort of reasons fundamentalism, it faces the question of why it does not begin in what seems, from the perspective of our story, the obvious place - namely, the faculty of reason itself. ${ }^{41}$ As we noted above, this is certainly where Kant himself would have started. And I don't think contemporary Kantians has provided a compelling answer to why their shift in emphasis from reason to agency represents an advance over Kant's own views. In short, viewed from the perspective of the present paper, a good deal of contemporary Kantianism can easily appear as a sort of distorted reflection of the traditional conception of rationality we have been discussing.

To be sure, none of this represents a clear objection to these views. But it does, I think, provide a context that should encourage us to carefully consider why the concepts of reason as faculty and reasoning as the activity of that faculty were for so long taken to be central to the network of concepts we have been discussing. Of course, we should not in general treat the past as authoritative for these sorts of philosophical debates, but at the same time, we should perhaps be cautious to assume that we can neatly sever some elements of this network of concepts from the others, without undermining all of the concepts in the network.

${ }^{41}$ As in, most famously, Korsgaard(2009). For an overview of this debate, see Schafer(2015a,b). 


\section{REFERENCES}

Anscombe, E. "Modern Moral Philosophy." Philosophy 33(124), 1958.

Daston, L. Classical Probability and the Enlightenment. Princeton: Princeton University Press, 1988.

\& Erickson, P. \& Klein, J. \& Lemov, R. \& Sturm, T. \& Gordin, M. How Reason Almost Lost its Mind. Chicago: University of Chicago Press, 2013.

Dogramaci, S. "Communist Conventions for Deductive Reasoning." Nous 49(4): 776-799, 2015.

DreIER, J. "Can Reasons Fundamentalism Answer the Normative Question?" in G. Björnsson et al (eds.) Motivational Internalism. Oxford: Oxford University Press, 2014.

FODOR, J. The Modularity of Mind. Cambridge: MIT Press, 1983.

GibBARD, A. Wise Choices, Apt Feelings. Oxford: Oxford University Press, 1990.

Habermas, J. (The Philosophical Discourse of Modernity. Cambridge: MIT Press, 1985.

HACKING, I. The Emergence of Probability. Cambridge: Cambridge University Press, 1975.

Herman, B. The Practice of Moral Judgment. Cambridge: Harvard University Press, 1993.

Hume, D. A Treatise of Human Nature. M. Norton \& D. Norton (eds.) Oxford: Oxford University Press, 2000.

Kant, I. Practical Philosophy. M. Gregor (ed.) Cambridge: Cambridge University Press, 1999. 
KAUPPINEN, A. (forthcoming) "Rationality as the Rule of Reason." Nous.

KIESEWETTER, B. The Normativity of Rationality. Oxford: Oxford University Press, 2017.

KorsgaARD, C. Self-Constitution: Agency, Identity, and Integrity. Oxford: Oxford University Press, 2009.

KREMM, D. and SCHAFER, K. "Metaethical Quietism." in T. McPherson \& D. Plunkett (eds.) The Routledge Handbook of Metaetbics. London: Routledge, 2016.

LaPlace, P.. A Philosophical Essay on Probabilities. New York: Dover Publications, 2012.

LEVINE, D. "The Continuing Challenge of Weber's Theory of Rational Action." in C. Camic, P. Gorski, \& D. Trukek (eds.) Max Weber's Economy and Society: A Critical Companion. Stanford: Stanford University Press, 2005.

LORD, E. The Importance of Being Rational. Oxford: Oxford University Press, 2018.

McHugh, C. \& WAy, J. "What is Reasoning." Mind 127: 167-96, 2018.

Mercier, H. \& Sperber, D. The Enigma of Reason. Cambridge: Harvard University Press, 2017.

PARFIT, D. On What Matters. Oxford: Oxford University Press, 2011.

RAwls, J. A Theory of Justice. Cambridge: Belknap/Harvard University Press, 1971.

SAYRE-McCorD, G. "Hume on Practical Morality and Inert Reason." in R. Shafer-Landau (ed.), Oxford Studies in Metaethics. Oxford: Oxford University Press, 2008. 
SCANLON, T. Being Realistic about Reasons. Oxford: Oxford University Press, 2013.

SCHAFER, K. "Doxastic Planning and Epistemic Internalism." Synthese 191:12: 2571-2591, 2014.

"Realism and Constructivism in Kantian Metaethics

2: The Kantian Conception of Rationality and Rationalist Constructivism," Philosophy Compass 10: 10: 702-713, 2015a.

"Realism and Constructivism in Kantian Metaethics

1: Realism and Constructivism in a Kantian Context."

Philosophy Compass 10:10: 690-701, $2015 \mathrm{~b}$.

"Hume and Practical Reason: Against the Normative Authority of Reason." in The Oxford Handbook of David Hume, P. Russell (ed.) Oxford: Oxford University Press, 2015c.

(forthcoming-a) "Constitutivism about Reasons: Autonomy and Understanding" forthcoming in The Many Moral Rationalisms (with Oxford University Press).

(forthcoming-b) "Rationality: The Capacity for Understanding.” Nous. (forthcoming-c) "A Kantian Virtue Epistemology." Synthese.

Schellenberg, S. The Unity of Perception: Content, Consciousness, Evidence. Oxford: Oxford University Press, 2018.

SETIYA, K. "What is a Reason to Act?" Philosophical Studies 167 (2):221-235, 2014.

SilversteIN, M. "Reducing Reasons." Journal of Ethics and Social Philosophy 10 (1): 1-22, 2016.

SMiTH, M. The Moral Problem. Oxford: Wiley-Blackwell, 1995. 
"A Constitutivist Theory of Reasons: Its Promise and Parts" in LEAP: Law, Ethics, and Philosophy 1: 930, 2013.

WALDMAN, T. "Origins of the Legal Doctrine of Reasonable Doubt." Journal of the History of Ideas 20(3): 299-316, 1959.

Weber, M. "Politics as a Vocation." in P. Lassman \& R. Speirs (eds.) Weber: Political Writings, Cambridge: Cambridge University Press, 1994. The Protestant Ethic and the Spirit of Capitalism. P. Baehr \&. G. Wells (eds.) New York: Penguin Books, 2002.

WeDgWOOD, R. The Value of Rationality. Oxford: Oxford University Press, 2018.

WUNDT, W. Principles of Physiological Psychology. London: Allen, 1983.

\section{(cc) $\mathrm{BY}$}

